\title{
Xenoreactivity and engraftment of human mesenchymal stem cells transplanted into infarcted rat myocardium
}
K. H. Grinnemo, $M D^{\mathrm{a}}$
A. Månsson, $M D^{b}$
G. Dellgren, $\mathrm{MD}, \mathrm{PhD}^{\mathrm{a}}$
D. Klingberg, $\mathrm{MSc}^{\mathrm{a}}$
E. Wardell, $\mathrm{BSc}^{\mathrm{b}}$
V. Drvota, MD, PhD
C. Tammik, BSc ${ }^{c, d}$
J. Holgersson, $\mathrm{MD}, \mathrm{PhD}^{\mathrm{C}}$
0 . Ringdén, $M D, P h D^{c, d}$
C. Sylvén, MD, $P h D^{b}$
K. Le Blanc, MD, $\mathrm{PhD}^{\mathrm{c}, \mathrm{d}}$

From the Departments of Cardiothoracic Surgery and Anaesthesiology, ${ }^{\text {a }}$ Cardiology, ${ }^{\mathrm{b}}$ Clinical Immunology, ${ }^{\mathrm{c}}$ and Center for Allogenic Stem Cell Transplantation and Clinical Research Center, ${ }^{\mathrm{d}}$ Huddinge University Hospital, Karolinska Institutet, Stockholm, Sweden.

The Swedish Medical Research Council, the Swedish Heart and Lung Foundation, the Belvén Foundation, the Tobias Foundation, the Tore Nilsson Foundation, and the Swedish Medical Society supported this study.

Received for publication Nov 6, 2002; revisions requested June 13, 2003; accepted for publication July 13, 2003.

Address for reprints: Göran Dellgren, MD, Departments of Cardiothoracic Surgery and Anaesthesiology, Huddinge University Hospital, S-141 86 Stockholm, Sweden (Email: goran.dellgren@thsurg.hs.sll.se).

J Thorac Cardiovasc Surg 2004;127:1293-300

$0022-5223 / \$ 30.00$

Copyright () 2004 by The American Association for Thoracic Surgery

doi:10.1016/j.jtcvs.2003.08.019
Objective: It is thought that adult human mesenchymal stem cells do not induce immunoreactivity even to xenografts. We wanted to study whether adult human mesenchymal stem cells survive and engraft in experimentally induced ischemic rat myocardium.

Methods: Bone marrow-derived adult human mesenchymal stem cells $\left(2.5 \times 10^{6}\right)$ were injected into the myocardium of 4 Sprague-Dawley rats. One week after injection, peripheral blood rat lymphocytes were added to adult human mesenchymal stem cells in a mixed lymphocyte reaction. Furthermore, an infarction was created by left anterior descending artery ligation of 8 Sprague-Dawley rats, 4 of which were immunosuppressed with tacrolimus $(0.1 \mathrm{mg} / \mathrm{kg} / \mathrm{d})$ and $4 \mathrm{RNU}$ athymic rats. One week after left anterior descending artery ligation, 2.5 to $3.5 \times 10^{6}$ adult human mesenchymal stem cells were injected around the infarcted area. The adult human mesenchymal stem cells were identified with fluorescence in situ hybridization technique and myocardial antigens by immunohistochemistry. The immune response was studied by hematoxylin and eosin staining and by antibodies directed toward macrophages.

Results: Significant rat lymphocyte proliferation was observed when adult human mesenchymal stem cells were added to peripheral blood from Sprague-Dawley rats previously exposed to adult human mesenchymal stem cells. No reactivity was seen in lymphocytes from untreated Sprague-Dawley rats and athymic rats. Adult human mesenchymal stem cells could only be identified in the myocardium of athymic rats. Further, in normal Sprague-Dawley rats, there was a significant myocardial infiltration of round cells, mostly macrophages, in the area of injection of adult human mesenchymal stem cells. In RNU rats, this reaction was less intense.

Conclusion: Adult human mesenchymal stem cells did not induce xenoreactivity in vitro in previously unexposed immunocompetent Sprague-Dawley rats. However, although mesenchymal stem cells are transplantable across allogeneic barriers, transplant rejection can occur in a xenogenic model. When transplanted into an immunoincompetent host, adult human mesenchymal stem cells showed persistent engraftment. 


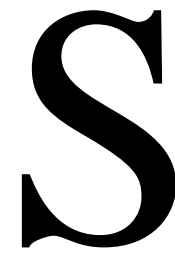

urvival of implanted cells and improved heart function has been reported after transplantation of fibroblasts, ${ }^{1}$ skeletal myoblasts, ${ }^{2-5}$ fetal and autologous cardiomyocytes, ${ }^{1,6-11}$ and bone marrow cells. ${ }^{12,13}$

Mesenchymal stem cells (MSC) are nonhematopoietic pluripotent cells present in adult bone marrow that can differentiate in vitro and in vivo to osteocytes, chondrocytes, adipocytes, and cardiomyocytes. ${ }^{14-16}$ Human MSC express intermediate levels of human leukocyte antigen (HLA) major histocompatibility complex (MHC) class I molecules and can be induced by interferon- $\gamma$ to express HLA class II and Fas ligand; they do not express the costimulatory molecules B7-1, B7-2, CD40, or CD40 ligand. ${ }^{17}$ They should therefore be recognized by alloreactive $\mathrm{T}$ cells. However, human, baboon, and murine MSC failed to elicit a proliferative response from allogeneic lymphocytes. ${ }^{17-21}$ When precultured with interferon- $\gamma$ for full HLA class II expression, MSC still escape recognition by alloreactive $\mathrm{T}$ cells. Unlike other nonprofessional antigen-presenting cells, this failure is not reversed by provision of CD28-mediated costimulation. ${ }^{17}$ Furthermore, MSC are immunosuppressive and inhibit T-cell alloreactivity induced in mixed lymphocyte cultures (MLC) or by nonspecific mitogens. ${ }^{17,18,20-22}$ MSC-induced T-cell suppression appears to include both naïve and memory $\mathrm{T}$ cells. It is dose-dependent and has no immunologic restriction because both autologous and third-party MSC equally reduce lymphocyte proliferation.

Given the unique immunologic properties of adult human MSC (ahMSC) and their ability to survive in the host after allogeneic transplantation, the purpose of the present study was to investigate whether ahMSC can engraft and survive in a xenogenic immunocompetent environment.

\section{Methods}

\section{Experimental Animals}

Fourteen Sprague-Dawley (SD) rats (B\&K Universal AB, Sollentuna, Sweden) weighing 400 to $450 \mathrm{~g}$ and $4 \mathrm{RNU}$ rats (Charles River Deutschland Inc, Sulzfeld, Germany) weighing 250 to $300 \mathrm{~g}$ were used altogether in this experiment. The Animal Care Committee at the Huddinge University Hospital approved all procedures. The animals received human care in compliance with the "Guide for the Care and Use of Laboratory Animals" prepared by the Institute of Laboratory Animal Resources, National Research Institute, and published by the National Academy Press. ${ }^{23}$

\section{Stem Cell Isolation Procedure}

To isolate ahMSC, bone marrow aspirates of 5 to $10 \mathrm{~mL}$ were taken from the sternum of patients undergoing a cardiac operation. The Ethical Committee at Huddinge University Hospital approved the study. MSC were isolated and cultured as previously reported. ${ }^{21,24}$ Mononuclear cells recovered from the interface of Percollseparated bone marrow were washed and resuspended in human
MSC medium consisting of Dulbecco's modified Eagle's mediumlow glucose (Life Technologies, Gaithersburg, Md) supplemented with 10\% fetal bovine serum (Sigma-Aldrich Corp, St Louis, Mo), $1 \%$ antibiotic-antimycotic solution (Life Technologies), and plated at $3 \times 10^{7}$ cells $/ 185 \mathrm{~cm}^{2}$ in Nunclon Solo flasks (Fisher Scientific, Pittsburgh, Pa). Cultures were maintained at $37^{\circ} \mathrm{C}$ in a humidified atmosphere containing $5 \% \mathrm{CO}_{2}$. When the cultures were near confluence, the cells were detached by treatment with trypsin and ethylenediaminetetraacetic acid (EDTA; GibcoBRL, Grand Island, NY) and replated (passaged) at a density of $1 \times 10^{6}$ cells per $185-\mathrm{cm}^{2}$ flask. After 3 passages, cells were harvested by treatment with $0.05 \%$ trypsin-EDTA and washed with phosphate-buffered saline solution (PBS).

By flow cytometry, cultured MSC were uniformly positive for CD166, CD105, CD44, CD29, SH3, and SH4 and negative for hematopoietic markers CD14, CD34, and CD45. On induction, the cells differentiated to osteoblasts, adipocytes, and chondrocytes, as previously described. ${ }^{21}$

\section{Anesthesia and Postoperative Care}

The rats were anaesthetized with an intramuscular injection of dormicum $(5 \mathrm{mg} / \mathrm{kg}$; F. Hoffmann-La Roche Ltd, Basel, Switzerland) and domitor vet $(0.1 \mathrm{mg} / \mathrm{kg}$; Orion Corp, Espoo, Finland) and were subsequently endotracheally intubated. Positive-pressure ventilation was maintained at a rate of 120 cycles per minute with a tidal volume of $1.5 \mathrm{~mL}$ with room air supplemented with oxygen ( $2 \mathrm{~L} / \mathrm{min}$ ) using a Zoovent ventilator (Model CWC600AP; BK Universal, Harvard, UK). The anesthesia was reversed by an intramuscular injection of lanexat $(0.1 \mathrm{mg} / \mathrm{kg} ; \mathrm{F}$. Hoffmann-La Roche Ltd) and antisedan vet ( $5 \mathrm{mg} / \mathrm{kg}$; Orion Corp). The rats were monitored for 2 hours postoperatively and then returned to their cages. The RNU rats were held under isolated conditions in specially designed cages with enhanced ventilation.

\section{Myocardial Scar Formation and ahMSC Implantation}

Under general anesthesia a left lateral thoracotomy and pericardiotomy was performed, exposing the heart. The left anterior descending artery (LAD) was identified and ligated with a 7-0 polypropylene suture. The thoracotomy was closed with running sutures of vicryl and the left pleura was deaired with a $10-\mathrm{mL}$ syringe. After 1 week the rats underwent a rethoracotomy and the infarcted area was identified. The ahMSC were suspended in 100 $\mu \mathrm{L}$ PBS and subsequently injected into the myocardium surrounding the infarcted scar. The control rats were injected with $100 \mu \mathrm{L}$ PBS without any ahMSC. The thoracotomy was closed in the same manner as earlier described and the anesthesia was reversed. The RNU rats were operated under sterile conditions in a ventilated chamber. The SD rats were operated under clean but nonsterile conditions.

The rats were divided into 3 groups with 4 rats in each. Three rats in each group received ahMSC and the remaining rat functioned as a control and received $100 \mu \mathrm{L}$ PBS. Group 1 was SD rats who were not immunosuppressed, and group 2 was SD rats immunosuppressed with tacrolimus $(0.1 \mathrm{mg} / \mathrm{kg} / \mathrm{d}$; Fujisawa Healthcare, Inc, Deerfield, Ill) given intramuscularly. These 2 groups received $3.5 \times 10^{6}$ ahMSC. Group 3 was athymic RNU rats, without the need of immunosuppression, who received $2.5 \times 10^{6}$ ahMSC. 


\section{Detection of Transplanted Cells and Evaluation of Differentiation Markers}

One week after the intracardiac injection of ahMSC, the hearts were removed, rinsed with PBS, and fixed in buffered formalin solution for 24 hours. The hearts were then embedded in paraffin and cut into $3-\mu \mathrm{m}$ thick sections by the use of a microtome (Microm, HM 355S, Microm Laborgeräte GmbH, Walldorf, Germany). The sections were subsequently prepared for hematoxylin and eosin staining to identify the site of injection and thereby identify the area with the implanted cells. It was reasoned that detection of DNA sequences specific for the human genome would provide unequivocal genetic evidence for identification of grafted cells. The fluorescent in situ hybridization technique (FISH) was used, allowing the detection of specific nucleic acid sequences in histological sections. The FISH procedure has been previously described $^{7}$ and in brief our modified version involves the following steps. The paraffin slides were baked at $60^{\circ} \mathrm{C}$ for 2 hours, the paraffin was removed, and a rehydration process was performed using $95 \%, 70 \%$, and $50 \%$ ethanol, respectively. The slides were microwave-treated in citrate buffer $(10 \mathrm{mmol} / \mathrm{L}, \mathrm{pH}$ 6.0) for 1.5 minutes at $750 \mathrm{~W}$ followed by 4.5 minutes at $50 \mathrm{~W}$. A mixture of $0.5 \mathrm{~mL}$ of pepsin (Sigma p7012) and $50 \mathrm{~mL}$ of $\mathrm{HCl}(150 \mu \mathrm{g} / \mathrm{mL})$ was applied to each slide and incubated at $37^{\circ} \mathrm{C}$ for 15 to 20 minutes and in $2 \times$ sodium citrate-sodium chloride buffer (SSC) with $0.1 \%$ igepal (Sigma-Aldrich Corp) for 10 minutes. The slides were then incubated in $1 \%$ formaldehyde $/ 50 \mathrm{mmol} / \mathrm{L} \mathrm{MgCl}_{2} / \mathrm{PBS}$ for 10 minutes at $20^{\circ} \mathrm{C}$ and in PBS for another 5 minutes, followed by dehydration. Then $3 \mu \mathrm{L}$ FISH probe cocktail (Vysis Inc, Downers Grove, Ill) was applied to each section. The next step consisted of simultaneous denaturation of probe and target DNA at $74^{\circ} \mathrm{C}$ for 10 minutes. The slides were subsequently incubated overnight in a humidified chamber at $39^{\circ} \mathrm{C}$ to allow hybridization of probe and target DNA. After repeated washes, the remaining probe molecules were stained with antifade containing 4,6-diamino-2-phenylindole. Slides were then examined using an Olympus DP10 fluorescent microscope (Olympus BX60, Olympus Optical Co, Ltd, Tokyo, Japan) where the nuclei of the transplanted cells stained red.

Slides with transplanted cells, identified with the FISH procedure, were incubated with antibodies directed against cardiacspecific antigens. The sections were rinsed in PBS and blocked by incubating the sections in 5\% rabbit serum (X0902, Dako, Glostrup, Denmark) for 30 minutes. The slides were incubated overnight at room temperature with mouse monoclonal antibodies specific for desmin (clone DE-R-11, Dako), sarcomeric actin (clone 5C5, Sigma-Aldrich Corp), myosin (clone NOQ7.5.4D, Sigma-Aldrich Corp), tropomyosin (T9283 clone CH1, SigmaAldrich Corp), and connexin 43 (clone CXN-6, Sigma-Aldrich Corp). The sections were incubated with fluorescence-labeled rabbit anti-mouse antibodies in the blocking solution at the dilution 1:10 (fluorescein isothiocyanate [FITC]-labeled, F0313, Dako) and visualized by fluorescence microscope.

\section{Immunohistochemical Characterization of Graft- Infiltrating Cells}

Cellular infiltration was detected by hematoxylin and eosin staining. Paraffin sections with lots of round cells were further stained with antibodies against macrophages. The paraffin was removed in xylene and rehydrated in ethanol $(95 \%, 70 \%, 50 \%)$ and in distilled water for 2 minutes each. The slides were then treated in citrate buffer $(10 \mathrm{mmol} / \mathrm{L}, \mathrm{pH} 6)$ in the microwave at $750 \mathrm{~W}$ for 1 minute and then for 5 minutes at $50 \mathrm{~W}$. The sections were incubated in 2 $\times$ SSC with $0.1 \%$ igepal for 10 minutes at $37^{\circ} \mathrm{C}$ then were incubated overnight at $20^{\circ} \mathrm{C}$ with the primary antibody (mouse anti-rat ED1MCA341R, Serotec, Oxford, England), diluted 1:40 in permeabilization buffer (Dako). After washing in $1 \times$ PBS, the slides were incubated with the secondary fluorescence-labeled rabbit anti-mouse antibody, diluted 1:20 in permeabilization buffer (FITC-labeled, F0313, Dako) for 2 hours, and then visualized in the fluorescence microscope.

\section{Mixed Rat Lymphocyte Human MSC Cultures}

To evaluate whether the ahMSC elicit an immune response or not, mixed lymphocyte reaction (MLR) test was performed on peripheral blood (PBL) from SD rats injected with $2.5 \times 10^{6}$ ahMSC. A separate experiment was performed with $5 \mathrm{SD}$ rats. Blood from 3 of the rats who received ahMSC were pooled, and blood samples from the other 2 rats ( 1 control) were tested separately. We also collected peripheral blood from 1 rat in each of the 3 groups described above, including 1 control rat who received PBS. This was done at the same time as these rats were killed and the hearts taken out for further analysis. Lymphocytes from each sample were separated on a Ficoll-Isopaque density gradient (Lymphoprep, Nyco, Norway). The cells were washed twice and suspended in Roswell Park Memorial Institute (medium) with fetal calf serum 5\%, mercaptoethanol $10^{-5} \mathrm{~mol} / \mathrm{L}$, and antibiotics. MLR was performed as previously described. ${ }^{21}$ In short, $1 \times 10^{5}$ responder cells were cocultured with $1 \times 10^{5}$ irradiated stimulator cells, which were inactivated by $20-\mathrm{Gy}$ irradiation. To each culture, $0,1 \times 10^{3}$ or $1 \times 10^{5}$ ahMSC were added. ${ }^{3} \mathrm{H}$-thymidine (Radiochemical Center, Amersham, UK) with a specific activity of $5 \mathrm{Ci} / \mathrm{mmol} / \mathrm{L}$ was added to each culture 24 hours prior to harvest. The cells were harvested automatically on a glass fiber filter using a Tomtec harvesting machine (Tomtec, Orange, Conn) on day 6. Tritiated thymidine incorporation is expressed as counts per minute (cpm).

\section{Results}

\section{Myocardial Infarction Model}

One SD rat died 2 days after the intramyocardial cell injection. The other rats survived the whole process without any apparent signs of discomfort.

\section{Histological Analysis}

The LAD ligation led to a transmural infarction in the anterior wall of all examined rats. Fibrous scar tissue had developed in the infarction area, visualized in hematoxylin and eosin staining (Figure 1). The implanted ahMSC were detected in large amounts in the myocardium of RNU rats (Figure 2), but they could not be found in SD rats. The implanted cells stained negative for all the monoclonal antibodies specific for cardiomyocyte antigens and connexin 43. In histological sections the implanted cells seem 


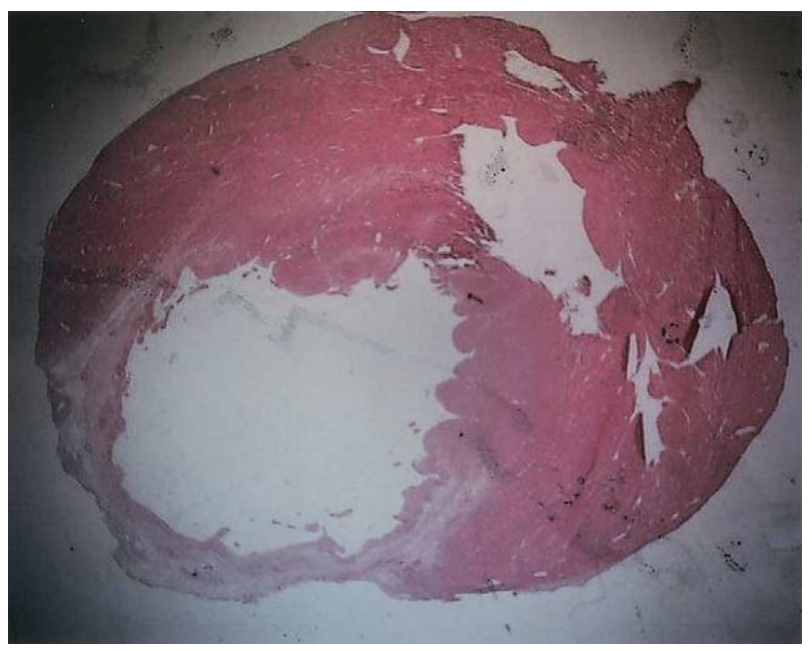

Figure 1. Representative photomicrograph of a transmural scar lesion, 1 week after LAD ligation in an SD rat. (Hematoxylin and eosin, $\times 10$.)

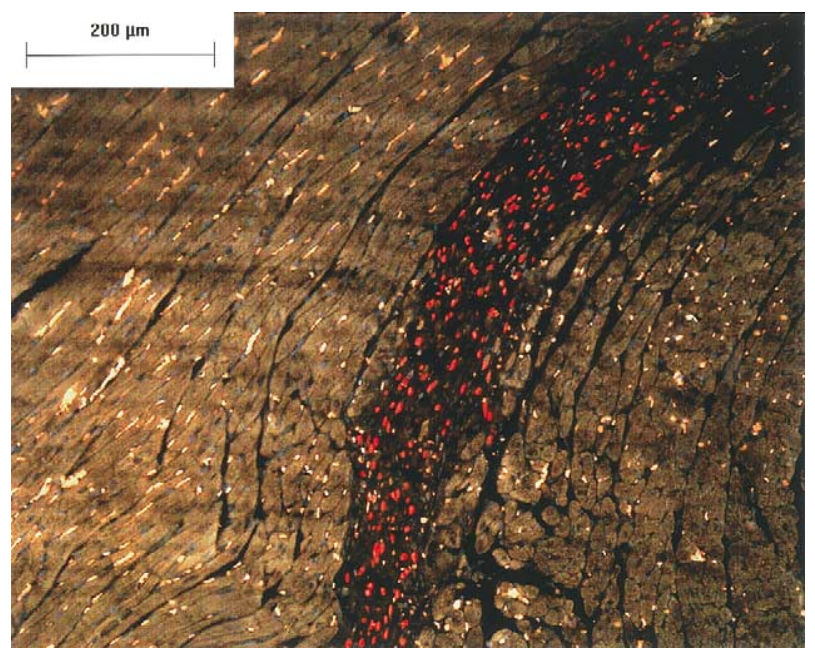

Figure 2. Identification of transplanted ahMSC 1 week after transplantation in an RNU rat. In situ hybridization of the chromosomes in the transplanted ahMSC stains red.

to be randomly dispersed in a disorganized way, without any sign of alignment, around the infarcted area.

\section{MLR and Cellular Immune Response}

In the first set of experiments, PBL from SD rats collected 7 days after cardiac injection of ahMSC were mixed with $1 \%$ or $10 \%$ ahMSC. ${ }^{3} \mathrm{H}$ thymidine uptake was measured and compared with that of the control rat (with no previous exposure to ahMSC). In the first set of experiments, ahMSC were injected into the myocardium of SD rats without LAD ligation. As shown in Figure 3, significant lymphocyte proliferation $(P<.01)$ was observed when ahMSC were cocultured with lymphocytes from SD rats previously exposed to ahMSC. No immune response was detected in animals not previously exposed to ahMSC.

To evaluate if ahMSC induced a sensitization reaction in SD rats immunosuppressed with therapeutic levels of tacrolimus and in RNU rats, PBL from these rats in the infarction model were analyzed in MLR. Lymphocyte proliferation was not significantly increased in PBL from SD rats with immunosuppression when exposed to ahMSC. The ahMSC did not elicit any proliferation in lymphocytes from RNU rats (Figure 4). However, significant proliferation was observed in animals without immunosuppression postahMSC injection, indicating a sensitization reaction.

In normal SD rats, without immunosuppression, there was an intense cellular immune response in the area of injection of stem cells, mediated primarily by macrophages (Figures 5 and 6). This cellular immune response increased significantly from day 2 to day 7 . We could not demonstrate almost any macrophage infiltration in SD rats immunosuppressed with tacrolimus. The macrophage-mediated immune response was significantly less prominent in the immunoincompetent RNU rats (Figure 6).

\section{Discussion}

In the present study, we investigated the fate of adult human bone marrow-derived MSC after injection into immunocompetent SD rats, with or without immunosuppression. ahMSC were also injected into the heart of athymic RNU rats that have an impaired response against xenogenic implants. We found that although ahMSC were present in all hearts 2 days postinjection, SD rats without immunosuppression, unlike the other animals, showed infiltration of inflammatory cells. One week posttransplant, ahMSC could no longer be detected in SD rats without tacrolimus. Immunofluorescence showed massive macrophage infiltration. In MLC, significant lymphocyte proliferation was observed when ahMSC were added to SD rats previously exposed to ahMSC, indicating an immune reaction against transplanted cells.

Numerous reports have indicated that MSC possess unique immunologic properties. Transplantation of allogeneic mismatched MSC to adult animals has shown engraftment in murine and baboon experimental models. ${ }^{25,26}$ In vitro studies of human MSC show that the cells fail to elicit proliferation of allogeneic lymphocytes even in the presence of CD28-mediated costimulation. ${ }^{17-21}$ The immunologic and multipotential characteristics of the cells used in the present study have previously been described in detail. ${ }^{21}$ The cells comprise a phenotypically homogenous population without contamination of hematopoietic cells. In coculture experiments, the cells do not elicit alloreactivity of autologous or allogeneic human lymphocytes. In MLC, they suppress the proliferation of $\mathrm{T}$ cells stimulated by cellular or 


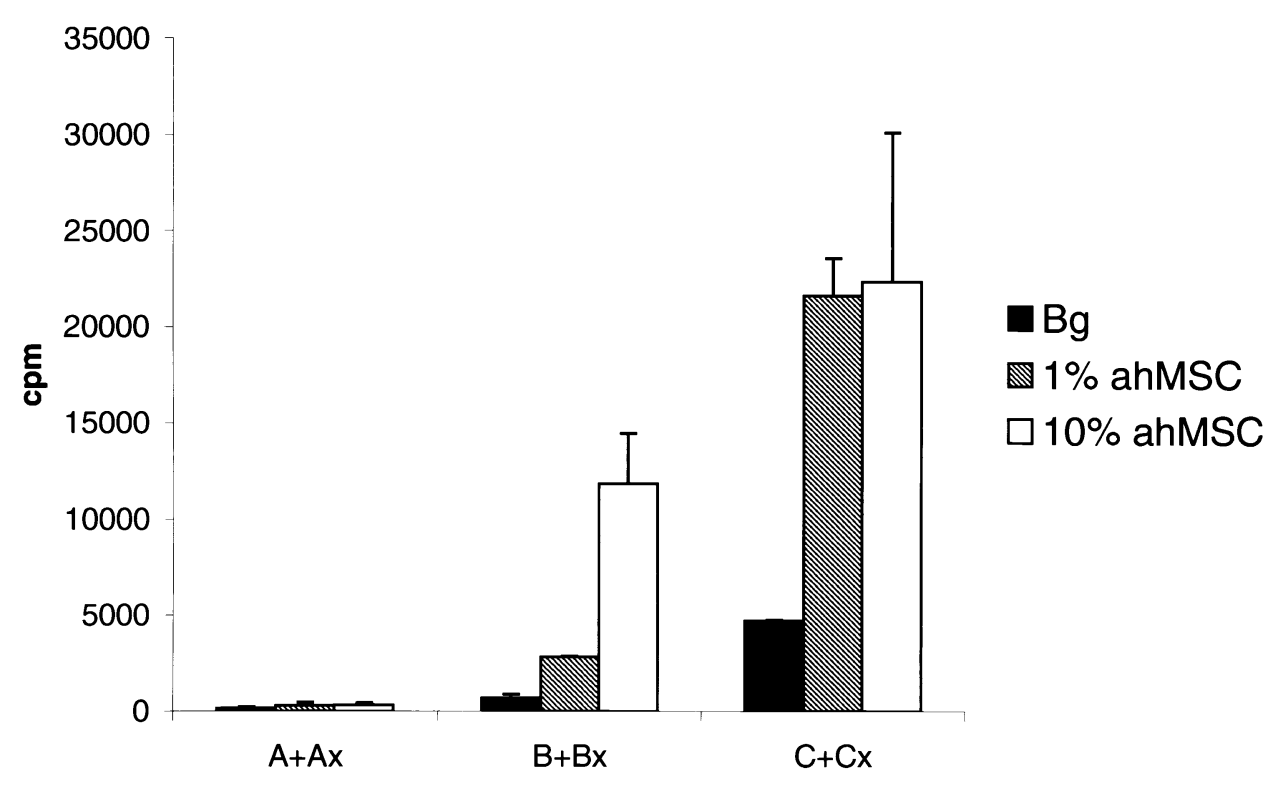

Figure 3. Responsiveness of SD rat lymphocytes to ahMSC 7 days after injection of ahMSC ( $B$, pooled peripheral blood from 3 syngenic rats; $C, 1$ individual rat) and with no previous exposure to ahMSC (A), as assayed by MLR. Experiments were performed in triplicate with a significance of $P<.01$. Mean \pm SD.

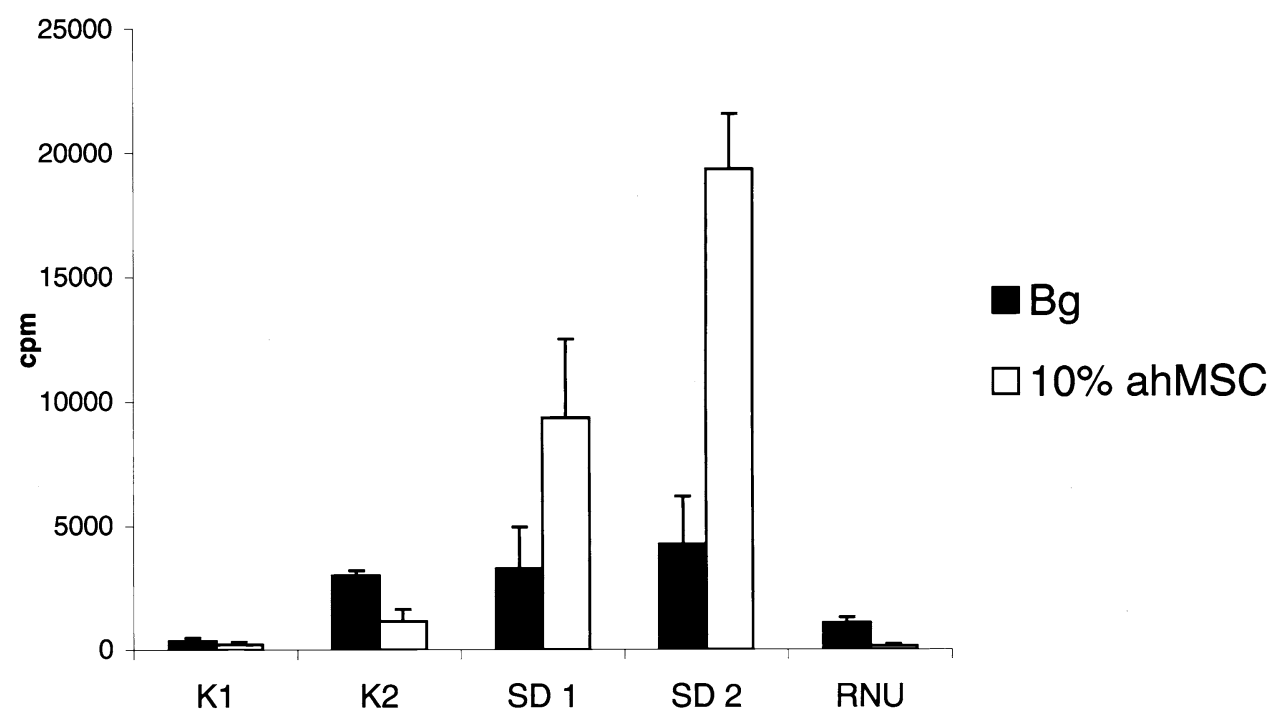

Figure 4. ahMSC elicit a significant proliferative response when cultured with PBL from SD rats but not from RNU rats previously exposed to ahMSC $(P<.01)$. Rat PBL $\left(1 \times 10^{5}\right)$ were cultured with $1 \times 10^{5}$ irradiated autologous lymphocytes in the absence (Bg, Background) or presence (MSC) of $1 \times 10^{4}$ ahMSC. Each bar depicts 1 experiment performed in triplicate. $K$, control animals; SD, PBL from SD rats 7 days post-cardiac injection of ahMSC; RNU, PBL from an athymic RNU rat 7 days post-cardiac injection of ahMSC. Mean \pm SD.

humoral antigens in a dose-dependent manner. Further characterization of the cells after differentiation in vitro has shown that MSC differentiated into adipose, bone, and cartilage express HLA class I but no longer express class II after interferon- $\gamma$ exposure. ${ }^{27}$ The differentiated cells are not inherently immunogenic. Instead, differentiation, partic- ularly along the osteogenic lineage, enhances the suppressive effect in third-party MLC. Moreover, the immunomodulatory effect of undifferentiated and differentiated MSC is further enhanced after treatment with interferon- $\gamma$.

In accordance with our previous results on allogeneic human lymphocytes, no proliferation was detected when 

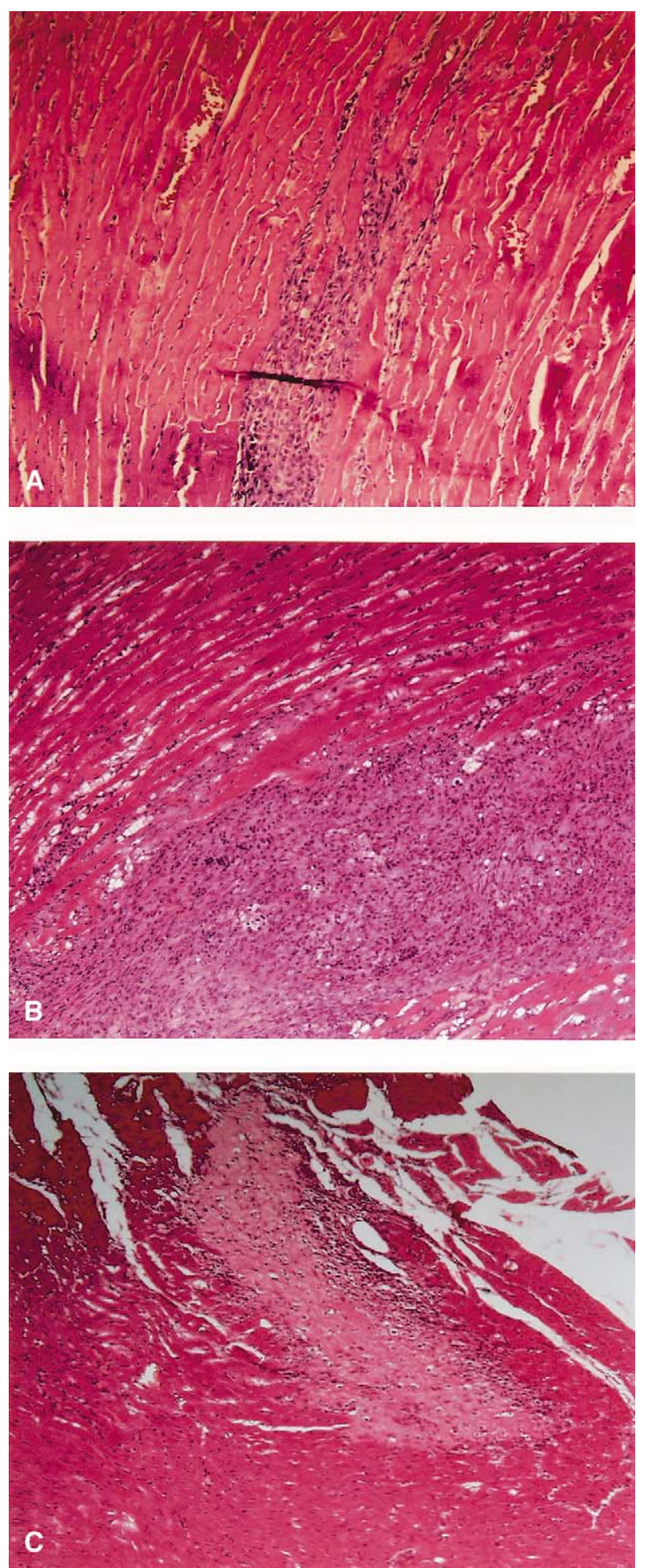

Figure 5. Round cell infiltration in the myocardium of normal SD rats: (A) 2 days and (B) 1 week after injection of stem cells and $(C)$ in immunosuppressed SD rats. (Hematoxylin and eosin, $\times 20$.)
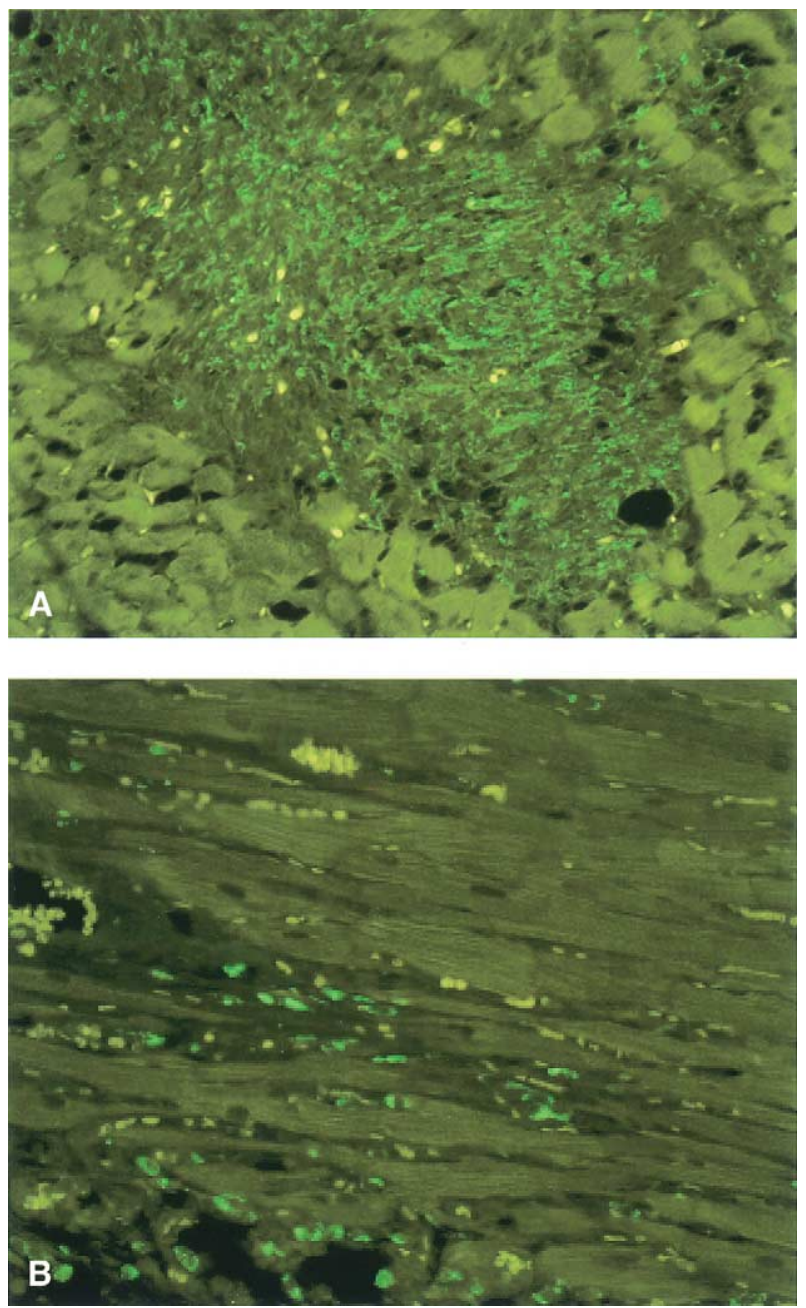

Figure 6. Immunofluorescence showing infiltration of macrophages (green spots) at the site of injection of stem cells in (A) normal SD rats and (B) RNU rats.

ahMSC were cocultured with SD rat lymphocytes. However, in immunocompetent animals that had received an injection of ahMSC, significant proliferation was observed in coculture experiments. This indicates that an immune reaction had occurred against the transplanted cells. The finding differs from results obtained after allogeneic transplantation of ahMSC in humans. No alloreactive proliferation can be detected when patient lymphocytes are reexposed to the transplanted allogeneic ahMSC in cocultures (Le Blanc and colleagues, unpublished observation). As expected, no T-cell proliferation was induced in rechallenged RNU rats that lack the ability to mount an adaptive immune response.

Histological examination of sectioned hearts further supported a rejection of transplanted ahMSC in SD rats. Round cell infiltration was noted 2 days posttransplant and was massive after 1 week. Transplanted ahMSC could be found 
on day 2 but not after 1 week. Infiltrating cells stained positive for macrophage markers. In SD rats treated with tacrolimus and in RNU rats, the macrophage infiltration was less prominent.

Mixed lymphocyte cultures are in vitro measures of the CD4 and CD8 T-cell proliferation in the lymph node initiated by antigen-presenting cells. Following xenotransplantation, in vivo immune responses include both acquired immunity and innate immunity, in which natural antibody, complement, natural killer cells, and macrophages all play independent roles. ${ }^{28}$ In accordance with this, in our system, we observed round cell infiltration that stained positive for macrophages at the time that the grafted cells disappeared. The paraffin-embedded material did not allow staining with antibodies specific for lymphocyte subsets, immunoglobulin deposition, or complement to study the mechanism whereby rejection occurred. However, the combination of these findings, the persistence of transplanted cells in athymic rats and an immunologic response when lymphocytes from transplanted immunocompetent animals were reexposed to ahMSC, strongly indicates rejection rather than unspecific inflammation. The mechanism behind the rejection will be the subject of future studies.

Our findings contrast with the results of Saito and colleagues, ${ }^{29}$ who reported on immunologic tolerance to mouse MSC allowing engraftment in the injured myocardium of immunocompetent rats, suggesting that the cells impart tolerogenic properties in that xenogenic environment. This discrepancy could be explained by the fact that the transplanted cells were derived from different species. Although both human and murine MSC are immunosuppressive, major differences exist between MSC from the 2 species. Murine MSC, unlike their human equivalent, lack MHC class II expression. ${ }^{22}$ Furthermore, T-cell inhibition by murine MSC requires cell contact whereas the suppressive effect by human MSC appears to be mediated by a soluble factor (Le Blanc and colleagues, unpublished observation). ${ }^{17,20}$ After intrauterine transplantation of ahMSC into sheep, the cells showed long-term engraftment and differentiated along multiple mesenchymal lineages. ${ }^{14}$ It is of particular interest that engraftment occurred even when the transplant was performed after the fetuses became immunocompetent. However, species-specific differences in immunologic tolerance may exist between sheep and rodents that could account for the discrepant results. Furthermore, although the ahMSC were transplanted into the fetal sheep after the expected development of immunologic competence, transplanted ahMSC were detected in the thymic stroma. It therefore could be argued that the sustained engraftment of xenogenic MSC in the fetuses not only results from active suppression of host $\mathrm{T}$ cells but also from the development of central deletional tolerance.
Toma and colleagues ${ }^{13}$ demonstrated the potential of ahMSC to undergo cardiomyogenic differentiation in the heart of an immunoincompetent murine host, although engraftment was limited after direct injection. This agrees with our findings of large amounts of ahMSC in the immunoincompetent RNU rats. The ahMSC that survived in the RNU rats 1 week after implantation had not migrated within the myocardium and had not differentiated toward cardiomyocytes. Moreover, they did not communicate with each other through gap junctions. Wang and coworkers ${ }^{30}$ demonstrated the presence of connexin 43 after intracoronary delivery of MSC; however, these animals were sacrificed after 4 weeks. Furthermore, Tomita and colleagues ${ }^{31}$ found autologous porcine bone marrow cells 4 weeks after transplantation within the infarct region, which seemed to have sarcomeres and Z-bands as well as expressing troponin I. This indicates that not only do ahMSC survive after transplantation but also that they seem to differentiate toward cells that appear to be similar to cardiomyocytes. Therefore, our observation period of 1 week is likely to be too short for the ahMSC to differentiate toward cells with a myogenic phenotype.

In conclusion, we found that ahMSC did not induce xenoreactivity in vitro in previously unexposed immunocompetent SD rats. However, although MSC are transplantable across allogeneic barriers, transplant rejection can occur in a xenogenic model. When transplanted into an immunoincompetent host, ahMSC showed persistent engraftment.

\section{References}

1. Sakai T, Li R-K, Weisel RD, et al. Fetal cell transplantation: a comparison of three cell types. J Thorac Cardiovasc Surg. 1999;118: 715-25.

2. Atkins BZ, Matthew T, Hueman BS, et al. Myogenic cell transplantation improves in vivo regional performance in infarcted rabbit myocardium. J Heart Lung Transplant. 1999;18:1173-80.

3. Taylor DA, Atkins BZ, Hungspreugs P, et al. Regenerating functional myocardium: improved performance after skeletal myoblast transplantation. Nat Med. 1998;4:929-33.

4. Rajnoch C, Chachques J-C, Berrebi A, Bruneval P, Benoit MO, Carpentier A. Cellular therapy reverses myocardial dysfunction. J Thorac Cardiovasc Surg. 2001;121:871-8.

5. Menasche P, Hagege AA, Scorsin M, et al. Myoblast transplantation for heart failure. Lancet. 2001;357:279-80.

6. Scorsin M, Hagege A, Vilquin JT, et al. Comparison of the effects of fetal cardiomyocyte and skeletal myoblast transplantation on postinfarction left ventricular function. J Thorac Cardiovasc Surg. 2000; 119:1169-75.

7. Scorsin M, Hagege AA, Marotte F, et al. Does transplantation of cardiomyocytes improve heart function of infarcted myocardium? Circulation. 1997;96(Suppl II):II-188-93.

8. Li RK, Mickle DA, Weisel RD, et al. Natural history of fetal rat cardiomyocytes transplanted into adult rat myocardial scar tissue. Circulation. 1997;96(Suppl II):II-179-87.

9. Li RK, Jia ZQ, Weisel RD, et al. Cardiomyocyte transplantation improves heart function. Ann Thorac Surg. 1996;62:654-61.

10. Li RK, Weisel RD, Mickle DA, et al. Autologous porcine heart cell transplantation improved heart function after a myocardial infarction. J Thorac Cardiovasc Surg. 2000;119:62-8.

11. Sakai T, Li RK, Weisel RD, et al. Autologous heart cell transplantation 
improves cardiac function after myocardial injury. Ann Thorac Surg. 1999;68:2074-80.

12. Tomita S, Li RK, Weisel RD, et al. Autologous transplantation of bone marrow cells improves damaged heart function. Circulation. 1999; 100(Suppl II):II-247-56.

13. Toma C, Pittenger MF, Cahill KS, Byrne BJ, Kessler PD. Human mesenchymal stem cells differentiate to a cardiomyocyte phenotype in the adult murine heart. Circulation. 2002;105:93-8.

14. Liechty KW, MacKenzie TC, Shaaban AF, et al. Human mesenchymal stem cells engraft and demonstrate site-specific differentiation after in utero transplantation in sheep. Nat Med. 2000;6:1282-6.

15. Prockop DJ. Marrow stromal cells as stem cells for nonhematopoietic tissues. Science. 1997;276:71-4.

16. Pittenger MF, Mackay AM, Beck SC, et al. Multilineage potential of adult human mesenchymal stem cells. Science. 1999;284:143-7.

17. Tse WT, Pendleton JD, Beyer WM, Egalka MC, Guinan EC. Suppression of allogeneic T-cell proliferation by human marrow stromal cells: implications in transplantation. Transplantation. 2003;75:389-97.

18. Bartholomew A, Sturgeon C, Siatskas M, et al. Mesenchymal stem cells suppress lymphocyte proliferation in vitro and prolong skin graft survival in vivo. Exp Hematol. 2002;30:42-8.

19. Klyushnenkova E, Mosca JD, McIntosh KR. Human mesenchymal stem cells suppress allogeneic T-cell responses in vitro: implications for allogeneic transplantation. Blood. 1998;92:642a.

20. Di Nicola M, Carlo-Stella C, Magni M, et al. Human bone marrow stromal cells suppress T-lymphocyte proliferation induced by cellular or non-specific mitogenic stimuli. Blood. 2002;99:3838-43.

21. Le Blanc K, Tammik L, Sundberg B, Haynesworth SE, Ringdén O. Mesenchymal stem cells inhibit and stimulate mixed lymphocyte cultures and mitogenic responses independently of the major histocompatibility complex. Scand J Immunol. 2003;57:11-20.

22. Krampera M, Glennie S, Dyson J, et al. Bone marrow mesenchymal stem cells inhibit the response of naïve antigen specific T-cells to their cognate peptide. Blood. 2003;101:3722-9.

23. Guide for the care and use of laboratory animals. Washington, DC: National Academy Press; 1996.

24. Wang JS, Shum-Tim D, Chedrawy E, Chiu RC. The coronary delivery of marrow stromal cells for myocardial regeneration: pathophysiologic and therapeutic implications. J Thorac Cardiovasc Surg. 2001;122: 699-705.

25. Devine SM, Cobbs C, Jennings M, Bartholomew A, Hoffman R. Mesenchymal stem cells distribute to a wide range of tissues following systemic infusion into non-human primates. Blood. 2003;101:29993001.

26. Bruder SP, Kurth AA, Shea M, Hayes WC, Jaiswal N, Kadiyala S. Bone regeneration by implantation of purified, culture-expanded human mesenchymal stem cells. J Orthop Res. 1998;16:155-62.

27. Le Blanc K, Tammik C, Götherström C, Zetterberg E, Ringdén O. HLA-expression and immunologic properties of differentiated and undifferentiated mesenchymal stem cells. Exp Hematol. 2003;31: 890-6.

28. Zhang Z, Bédard E, Luo Y, et al. Animal models in xenotransplantation (review). Expert Opin Investig Drugs. 2000;9:2051-68.

29. Saito T, Kuang JQ, Bittira B, Al-Khaldi A, Chiu CJ. Xenotransplant cardiac chimera: immune tolerance of adult stem cells. J Thorac Cardiovasc Surg. 2002;74:19-24.

30. Wang JS, Shum-Tim D, Chedrawy E, Chiu RC. The coronary delivery of marrow stromal cells for myocardial regeneration: pathophysiologic and therapeutic implications. J Thorac Cardiovasc Surg. 2001;122: 699-705.

31. Tomita S, Mickle DA, Weisel RD, et al. Improved heart function with myogenesis and angiogenesis after autologous porcine bone marrow stromal cell transplantation. J Thorac Cardiovasc Surg. 2002;123: $1132-40$. 